\title{
CONSIDERATION OF CLIMATE IMPACT ON CONTEXTUAL ARCHITECTURE IN ARID REGIONS
}

\author{
Mehdi Mehrabi \\ University of Art and Architucture \\ Qeshm international Branch, Islamic Azad University
}

\begin{abstract}
Nowadays, one of the significant discussions in the field of architecture is designing of buildings based on their context. This context can have several different aspects such as historical-physical, social—cultural and/or climatic contexts. Climatic contextualism considered as one of significant discussions in architecture contextualism which is also resulted to sustainable building. The purpose of this research is consideration of climate impact on contextualism architecture. For this aim, Iran special arid climate is selected because of special architecture and similar to this climate. The approach of research is analytical-descriptive and data collection is performed by desk research. In this research, after recognition and analysis of related concepts to contextualism and contextual architecture, we study Iran arid climate and consider architecture of its buildings which is conformed with context totally. The results show that vernacular architecture in Iran arid climate is designed based on climatic context of it from different aspects like typology of buildings, urban texture, kind of materials, their colors and the way of designing buildings details.
\end{abstract}

Keywords: conceptualism, contextual architecture, climate, arid climate

\section{INTRODUCTION}

A building doesn 't need to exact imitation of figure and form from adjacent buildings for coordination with context and improvement of visual integration of region. In fact, it should have certain and common basic features. Designing into context don't mean necessarily uniformity. There is difference between visual variety which creates disorder and the variety in which we can see power. Both of disorder and uniformity are unpleasant. Evaluation of quality of context is one of the basic matters in contextualism that should be practiced (Brolin, 1980: 148-153).

Architecture in context is neither a neglect nor extremist innovation but it is powerful and eloquent visual communication with environment. A single building initially is considered as part of the whole. Creation of spaces and places which improve human life are the basis of the architects' job. Any building can be and should be beliefs and needs of special time and place in conversation and interaction with history. The value of each building depends on its environment. Existing spatial relations between building and environment are very important (Ghadiri, 2006, 13).

Uniformity and unity of components do not mean being together and liaising. Unity is achieved when the components of a plan are designed to attain certain purpose. Therefore, for proper understanding of a building and motivating human aesthetic, general understanding of it is necessary. And the condition of this unity and uniformity is liaising and coordinating of all forming components of an architecture plan like structure, architecture place etc. is necessary. In contextual architecture, the factors which bring unity for adjacent buildings are: skyline, distance among buildings, proportion of windows, prominences and indentations of building, doors and other elements, general form and figure of building, place and entrance interface way of building, materials kind, payment and texture of building, achieved shadow pattern from volume and decoration elements, building scale, architecture style and landscaping (Brolin, 1980: 148-153).

Using form patterns (historical-physical contextualism), behavioral patterns (social-cultural contextualism) and using climatic patterns (climatic contextualism) are three important aspects in contextual architecture. In this research, we study about climate particularly. For this aim, Iran arid climate is mentioned and its architectural features of buildings are considered. Climate is: explanation of atmospheric conditions that weather of certain region is determined by quality and evolution based on climatic meteorology culture. 
Climate is always studied by architects and planners as a natural phenomenon. The purpose of climatology is exploration and determination of natural behavior of atmosphere and exploitation of it for human benefits. About all human activities for continuity of life cycle are affected totally by weather and climate directly and indirectly.

In the history of architecture and building construction, designers and even architects always try to respond weather conditions. Traditionally, climatic design had masterly and exact expression either in buildings located in mountainous cities that protected against wind and south or in the plan of traditional central yard homes that are designed to maintain night cold in arid climate. In this vernacular buildings and local styles, climate and weather are considered as basis of human life and activities that finally form and beauty of buildings are achieved from them and it is also called climatic designing of building. It includes series of principles in designing of monuments by architects and designers which can result to optimum designing of spaces for calmness of human and saving energy. Climatic designing is an approach for multilateral reduction of energy of a building. The designing of the building is the first defensive line against external climatic factors of building (Shams \& KhodaKarami, 2010).

\section{RESEARCH METHODOLOGY}

The purpose of this research is consideration of climate impact on contextual architecture in arid regions. The approach is analytical-descriptive that used data in the research section of this project are achieved by desk research. Library data in this project are achieved by different approaches such as reference to magazines, books, research projects, maps and web search. In this section, we try to use the last available data related to studied subject. At first, concepts related to context and contextualism is introduced and then contextual architecture is presented. In the following, discussions about contextualism aspects are presented that is one of the most important of these aspects are climate aspect. According to this end, this research particularly considers arid climate of Iran. In the continuity of research, the characteristics of this climate are presented and its special architecture introduced. Finally, principles of designing and architecture of buildings are concluded according to context of arid climate.

\section{THEORETICAL CONCEPTS OF THE RESEARCH:} context and contextualism:

Context means ordering of an area or region. Architect Elil Saarinen (1956) has wrote: always design something by considering it in larger context, a chair in a room, a room in a home, a home in an environment and an environment in the city plan. Adrian Forti (2000) declared that origins of context, contextual and contextualism concepts established in Milan in the middle of 1950s. probably Forti refers the first considerable presence of context expression in dictionary of architecture to notes of Cristopher Alexander about form synthesis in 1964. Its meaning is synonym of environment instead of concepts which were achieved till now (Cowan, 2005: 88).

Contextualism is the view that points to particular characteristics of a place and its use in contemporary designing, the effort to show visual desirable environment and necessity of attention to physical environment around architectural effect, it begins from building itself, site or land in which it is located and introduced in the level of neighborhood and in fact distance from single architecture and near to urban planning, it has urban concept basically and means coordination among adjacent buildings (Brolin, 2007). Contextualism is based on this principle that a phenomenon cannot be imagined separately and solitary from environment and phenomena are not exclusive to their forces, essence and internal features but they depend on their environment and collection. Each phenomenon affects its environment and also affected by it and they interact with each other.

In fact, entire universe is interrelated and each component is effective on whole and any change in component will lead to change in the entire universe (Ahmadi, 2009).

Generally, contextualism is coordination and compatibility with physical, climatic, historical and culturalsocial contexts that according to it, contextual designer should be able to understand features of a place and take it as the part of his designing process (Toulaie, 2001). Designer and architect should understand context message and design bed. After that, he should design according to existing conditions and that designing 
should be based on realistic approach about environment information and building should create correct and equal interaction with its site (Ahmadi, 2009).

\section{Contextual architecture:}

This architecture does not emphasis on either imitation or a barrier to innovation and creativity. Its message is necessity of attention to physical environment of architectural effect and shows that this attention can be a positive and improving factor for both architectural effect itself and context. Contextual architecture is an effort for showing power of creation of desirable visual environment in larger scale rather than architecture. In the view of Edmund Biken, in the renaissance architecture, this matter is observed properly and assures success of urban spaces and views of this era. Visual relations are not mysterious features that can be understood by professional specialists but it is simple and initial features. Windows proportions, the place of entrance door, decoration elements, style, materials and skyline are the features that create unity or lack of unity and uniformity of a street, district or region. Any place has integration of these elements and degree of freedom for creating variety in designing. A building does not need to imitate exactly the form and figure of adjacent buildings for having proportion with context and improvement of visual unity of region but it should have mutual and certain basic features (Hossein Pour et al. 2013).

Robert Venturi (1966) questioned philosophical and worldview principles of modern architecture in the book of complexity and contradiction in architecture. He rejected techno approach and instead claimed for paying attention to human features and a humanist architecture. he considered international style as the dismissed style and instead believed contextualism. It means that any building should be designed based on its physical, historical, social and cultural contexts and special conditions of that site and buildings. It can be considered as vernacular style (Ghobadian, 1937:111). The message of contextual architecture is necessity of attention to physical environment of architectural effect and it shows that this attention can be positive and improving factor for both architectural effect and context. Contextual architecture is an effort to show power of creating desirable visual environment in larger scale rather than architecture. Here, artistic architect can play significant role in attention to context by new creation in exiting urban space. This matter increases his responsibility about urban environment (C. Brolin, 2004:1).

\section{contextualism dimensions:}

In paper "contextual architecture', Kardan Zirak \& Ashtari categorize contextualism as follows:

Contextualism in physical, historical, climatic and cultural-social contexts is further than only physical dimensions of recent decades that replaces concept of place with space. Contextualism is the link between architecture and urban planning in a certain context in which an architect effect is related to larger urban system and in hierarchical of collections leads to historical continuity that Rob Krier expresses it as anything which is performed in the city should be a response to pre-existing conditions materially (Toulaie, 2001).

Using form patterns (historical-physical contextualism)

Using behavioral patterns (social-cultural contextualism)

Using climatic patterns (climatic contextualism)

Of course, we can divide context to natural and urban contexts. For buildings in the nature, urban context lost its meaning and natural context is introduced. Natural context is soul, mood and environmental feature such as texture, color, kind topography and etc. also, this factors overlap with regionalism principles. For this reason, natural contextualism immediately integrates with regionalism and harmonizes with it. For natural contextualism, we can present good examples like Le Corbusier church and its attention to natural context or Vila Mayra by Aalto or Dipoli set by Pitila (Karda Zirak \& Ashtari, 2014: 19-20).

Physical contextualism: proximities, urban contexts (structuralism-old architecture)

Natural contextualism: coordination with nature etc. (Folding architecture- deconstruction and post structuralism). 
Naser Ghanbari, in his research as "comparative consideration of contextualism approaches in architecture of cultural contemporary buildings of Iran and west, introduces another type of categorization.

\section{Physical conceptualism}

The elements like form and figure, scale, proportions, details of materials, texture, colors, geometry, accessibilities, directions, perspectives, topography of the place, vegetation, urban texture including amount of buildings density-streets and pavements and their relations, type of materials, integration of materials, integration of volumes and forms with each other, organization of spaces, adjacency of buildings with each other, linking of old and new buildings, skyline, line and type of connection to ground and many other similar matters (Ghanbari, 2014:23).

\section{Historical contextualism}

Historical architecture and urban planning evidence indicate that in past, architecture and urban planning is formed in proportion with environment. Traditional architecture is created with tendency to ecological and social stability with respect to natural resources and protection of it for future. Regarding indestructible forces such as sun and wind and using them for improving thermal conditions of environment were usual form ancient times (Ghanbari, 2014:23).

\section{Climatic conceptualism:}

Regarding climate and climatic factors in which we establish can be jumping stage for flying to stable architecture. Attention to this matter smoothest the rout for using natural forces like sun, wind, water etc. and minimizes use of fossil resources. So, attention to climatic forces of region such as climatic characteristics of any context of wind, rain, changes of temperature in day and night, temperature, sky condition, sun, radiation etc. are necessary (ghanbari, 2014:23-24).

\section{Cultural contextualism:}

Regarding cultural, environmental elements, traditions and origins, conventions and cultural religion in any context and applying them in designing of architecture and urban planning and also place of users of building can help to use building. Therefore, attention to cultural values in any context and use of them will result to cultural contextualism (http://fa.wikipedia.org [Accessed on 03/October 2014: 8 pm).

Types of contextualism:

Physical: elements such as form and figure, scale, proportions, details of materials, texture, colors, geometry, accessibilities etc.

Historical: attention to old architecture and urban planning in proportion with environment and achieving social and ecological stability

Climatic: attention to climatic factors of region like climatic features of any context of wind, rain, changes of temperature in day and night etc.

Cultural: attention to cultural values in any context and applying them

Chart 1: chart of types of contextualism and their components (source: Ghanbari 2014: 24)

Meryl Guinness (1980) also categorizes context in architecture as three general subjects of form, activity and climate that all of them discussed below (Ghanbari, 2014:36):

Contextualism in architecture-form patterns-climatic patterns-activity patterns

Chart 2: categorization chart of context in architecture based on Meryl Guinness (Source: Ghanbari, 2014:36) 
1. Form patterns: here, form includes elements such as space, figure, scale and proportions of details of texture materials and colors. These elements can be used for relating architecture with its context in two geographical and time dimensions. Geographical dimension can be presented in three scales:

Connection of building with adjacent buildings in comprehensible and visible distance. Example of such connection with around context can be observed in urban views and new replacement in historical sites.

The next scale is when building connect not necessarily with environment but it connects with around site.

Third connection with site can be achieved in regional scale. In addition to visual and distance dimensions, building can connect with environment in time dimension (past, now and future). In center of Columbus, Peter Eisenman relates his geometry with a type of historical stratification from Site-Palimpsest to past of city although in these cases, understanding and exploring this relation with site is not obvious as previous cases.

2. Activity patterns: in the field of activities, circulation in site of building, individuals ' behavior and groups are the factors that can relate building with its context.

3. climatic patterns: climate shows its effect in materials, colors, pressure of volumes, forms and roofs etc. the art and sensitivity of architect, the amount of his understanding from physical and emotional-mental features of site or sense of place that is achieved only by presence and life in one place help architect to better understand and create this relation. This feature as a dark nature in site is explored by architect and interpreted. This nature converts site from its figure to something which it can be (Gaines, 1980). As we can observe in categorizations, attention to climate is one of the important factors in contextual architecture. in this research, arid climate in Iran is considered particularly that we will discussed below.

\section{PRESENTATION OF FINDINGS AND THEIR ANALYSIS: \\ climatic divisions in Iran:}

Principally, in many regions of the world, climate is determined by latitude and sea level. Iran is located in 25 and 40 degrees of northern latitude in hot region. Regarding height, it is elevated plateau that a total of its surfaces which their sea level is lower than 475 meters cover a little percentage of overall surface of the country. Despite Iran has two high water zones, (Caspian Sea and Persian Gulf), because of Zagros and Alborz range of mountains and their location, the impacts of these two zones is limited to their near regions and they seldom affect adjustment of temperature of internal sections. Undoubtedly, in mountainous country like Iran, two points never are similar. However, the best approach for achieving a base to determine climatic regions of state is Koppen principles that we should follow them inevitably. Therefore, quadruplet divisions of Iran that were introduced by Dr. Hassan Konji would not be used. He accepted Koppen classification by little changing with consideration of latitude complications of state as below (Pir Mohammadi, 2015):

1. Temperate and humid climate (southern beaches of Caspian Sea)

2. Cold climate (Western mountains)

3. Hot arid climate (central plateau)

4. Humid and hot climate (southern beaches)

5. Humid and temperate climate (southern beaches of Caspian Sea).

Iran arid and hot climate

Arid and hot climate exist in center of eastern areas of state generally. Its general characteristics are:

9. Arid and hot weather in summer and arid and cold in winter.

1. Little raining

8. Little humidity 


\section{Little vegetation}

\section{High difference of air degree in day and night}

1. in desert areas and desert margin, winds with cloud.

Because of little humidity and distance from sea, the difference of temperature of day and night is high and because of little water for agriculture and also residents' consumption and existence of high sand and soil, life is very hard. As there isn't any tree and little wood, creation of roof is difficult. But compatibility with these weather conditions in different seasons is observed in Iran traditional architecture properly. The indexes which are considered for achieving desirable calmness in Iran traditional architecture especially in hot and arid climate are extraversion, introversion, and orientation, declining into soil, four seasons' homes, using greenbelt, using proper materials, insulation and finally role of water in Iran traditional architecture (Zadeh Esmaiel \& Torabi Langari, 2012:3).

In this climate, winter is so cold whereas summer is so hot. Therefore, building should be designed to encounter with both dilemmas. Undesirable blast with cloud form desert and/or arid areas is another dilemma in this region. Urban texture should be designed compactly and urban spaces and pavements closed in order to prevent thermal flung in winter and cloud wind. Fluctuation of thermal temperature during day is high in this region although its amount is fewer than elevated regions (Ghobadian, 2002).

\section{vernacular architecture of Iran in arid climate}

Wind, rain, temperature, humidity and sun radiation are the factors which form perspectives and adjust people with climate historically. Human calmness and in some cases his survival depends on skill to which he creates buildings and spaces coinciding with climatic environments (Hough, 1993: 28).

Vernacular architecture shows irrefrangible relationship of human and nature by smoothing nature and using natural products (AlpaConovolo et al. 1986:60). Existing traditional homes in arid climate of Iran are one of obvious samples of coordination between human and nature. Climatic and unique features of arid regions cause formation of residences with special principles and development of smart theoretical techniques of duct and windy (Dehghan, 2003:66). Climatic calmness in these regions is provided by three ways: using shadow and wind, using water and reducing the effect of sun radiation (Golkar, 2001: 80). Also, climate is effective factor in formation of central yards in cities and vernacular and traditional architecture in arid climate. In this climate, because of presence of arid weather, sun radiation and special climatic conditions, cities have compact and compressed structure (Zare et al. 2012:53). This compactness protects influence of sunny radiations. Walls and roofs often considered thick in order to protect inner space from outer heat. Urban structure is designed as arteries were opened in desirable direction of wind and they were closed in undesirable direction of wind and sandstorm (Tavassoli, 1974). Compactness in the residential buildings converts to openness which is called central yards. Climatic impacts affected the process of formation of central yard by two factors: first, to create better climatic conditions, orientation of buildings was considerable. Second, buildings introverted to face climatic conditions (Zare et al. 2012:53). In introverted architecture, inner spaces did not have any relationship with urban spaces. Also, principally there isn't any casement to alley or passage in this type of architecture and/or if there was any casement, it would be established on high height in order to remove direct view (Dilman et al, 1987).

Main structure of traditional houses of Iran arid regions was formed of brick and bat. Thermal features of brick and bat are the effective factors on housing calmness. Brick-shaped and earthen homes act as insulator with their thick walls (Dehghan, 2003:70). Of important matters in construction of native homes of Iran arid regions is orientation of homes (home-oriented). This orientation performed based on the way of sun radiation and blasts (Pirnia, 1992:155). Orientation of old homes, based on climate, created the situation in which summer spaces and winter rooms located around the yard logically. In fact, this orientation resulted to multi-functional inner spaces such as north parts spaces and south parts spaces and caused inner migration in home (Memarian, 1992:347). Therefore, one of special adjustments is formed in arid environments. Settlement of rooms around yard is that summery rooms are always back of the sun and away from hot sun of summer afternoons. Summery rooms, in their desirable figure, have following components: one hall or porch, one springhouse, one basement and one Panjdari which is the biggest room of summery part and is 
used as sitting room of family. Winter rooms which are called sunny located in opposite direction of summery parts. It means that they opened to south part of yard in order to possess more winter sun (Kheir Abadi, 1997, 55-57).

Yard with gardens and the pool in middle of them are another arrangement which is considered for reducing intensity of heat. The yard which has lower surface than street surface of the city, in addition to providing light for rooms, acts as modifier for temperature. In winter nights that residents slept on the roofs, cold air which was run on the smooth roof of home simply enters into yard. During the day, this freshness was maintained and radiated on the floor of yard and cooled the home (Castello, 1992:40). In the center of yard of vernacular homes, there was a pool which attracted the solar energy. Gardens with droughty trees, in addition to beauty, supplying shadow and playing role in beauty, compensate poverty of environment humidity. In other words, all building elements of traditional residences cooperate to provide little and livable climate for human (Mostofi Almamaleki et al. 1996:119).

In most of homes of arid regions, there is basement. Designing of basement was that through connection with windy, yard, pool and garden can provide calm and desirable environment for rest in the hot summer of region. The best type of basement is that its door opened to the north because it remains safe from intense radiation of the sun in addition to using mild winds of north (Dehghan, 2003:72). Most of old homes had high walls that provide shadow in summer season in addition to safety advantages and finally relative freshness of motion paths (Hedaiat, 1995:712). Windy is also another component of housing that plays beneficial role in providing proper environment in summer season by natural ventilation act. The orientation of desirable winds determined shape and orientation of windy. Windy takes dominant summery winds and directs them into hall, basement, springhouse etc. through channels. Beneficial usage of windy caused that this technique transferred to Persian Gulf countries in $19^{\text {th }}$ century by Iranians (Bonine, 2001:51).

Generally, we can say that in this climate, plans are compressed and compact. Through this, outer surfaces of building minimize in comparison with its volume. Compactness and compression of plans and buildings minimize the amount of thermal interaction in winter and summer and caused that maximum shadow created on the surface. Most of opening surfaces and windows located to protected limitation of central yard which undergoes lower hard and drastic conditions of outer space of building. Type of used materials include high thermal usage and bright color and orientation is south to south-east (Saleh Pour et al. 2013).

Generally, it can be said that following items were observed in designing of buildings in Iran arid climate based on contextual architecture, particularly the climatic topic:

Construction of windy to direct wind into building

Construction of central yard and introvert architecture

Construction of garden hole

Buildings have compactness in plan to face sun radiation and settlement of fewer surfaces in front of sun

Construction of building to the south and south-east for optimum use of sun radiation energy in winter

Using high thermal resistance and thermal capacity materials such as whole and is components

High thickness of walls and use of bright color of materials to reflect sun light

Minimum number of openings in outer surfaces to pavements of humid and hot climate: high temperature and humidity, low raining, very hot and sultry summers, short and moderate winters, low difference of temperature during day and night are the characteristics of these regions. High heat and humidity, low raining, sultry and hot summers, minimum difference of temperature of day and low vegetation are the climatic feature of this region. In fact, it is linking circle of two introvert architecture of arid region and extrovert architecture of humid and moderate region since it has features of introvert architecture and extrovert architecture simultaneously (Kerdouni, 2010).

Table 1: architectural characteristics in arid climate 


\begin{tabular}{|l|l}
\hline \multicolumn{2}{|l}{ Features of contextual architecture in arid climate } \\
\hline $\begin{array}{l}\text { Introversion home with yard because of maintain energy } \\
\text { and compatible with climate }\end{array}$ & $\begin{array}{l}\text { The main forming } \\
\text { element of residential } \\
\text { pieces of urban texture }\end{array}$ \\
\hline Residential & Type of building \\
\hline Introvert & typology \\
\hline$-\quad \begin{array}{l}\text { Flat: } \\
\text { Oddness and dome: their convex and spherical } \\
\text { shape is suitable for radiating thermal radiation. During } \\
\text { the day and at morning and afternoon, half of dome is in } \\
\text { shadow of another half. this matter plays an important } \\
\text { role in reducing temperature of roof. Dome roof } \\
\text { encounters with wind because of its swellings. } \\
\text { Therefore, thermal radiation has lower effect on it. }\end{array}$ & \\
\hline$-\quad \begin{array}{l}\text { Creation of maximum shadow for roof } \\
\text { Reduction of thermal radiation roof }\end{array}$ \\
\hline $\begin{array}{l}\text { Creation of private space on roofs } \\
\text { Protection of roofs from desert winds }\end{array}$ & Shelter on the roof \\
\hline $\begin{array}{l}\text { Brick materials for walls structures } \\
\text { Beautiful integration of brick and wood }\end{array}$ & Type of materials \\
\hline Beautiful integration of brown and turquoise & Color of materials \\
\hline Compact and compressed texture & $\begin{array}{l}\text { Coordination } \\
\text { climate }\end{array}$ \\
\hline Pool, green belt, natural light of sun and wind & Nature element in yard \\
\hline
\end{tabular}

\section{CONCLUSION}

In this research, we consider the role of climate in contextual architecture in arid regions. At first, research concepts are introduced in relation to context and contextualism concepts. Then, contextual architecture is presented. In the following, topics of contextualism dimensions are introduced that one of this important dimensions of is climate dimension. In this research, we particularly discuss about climate in Iran arid climate and architecture of buildings of this climate are considered. The results show that Iranian architecture in this climate in the case of all physical different aspects like building typology, type of materials, color of materials and designing of single components is in full coordination with its context, particularly climatic context. at the end of research, all features of Iranian vernacular architecture features in arid climate are expressed. 